\title{
Mortality in Extremely Low-Birth-Weight Neonates in México City (1985-2009)
}

\author{
José Iglesias-Leboreiro, ${ }^{1,2}$ Isabel Bernardez-Zapata, ${ }^{1,2}$ José Ramírez-Haua, ${ }^{1,2}$ \\ Rocco González-Morán, ${ }^{1}$ and Mario Enrique Rendón-Macías ${ }^{2,3}$ \\ ${ }^{1}$ Unidad de Cuidados Neonatales, Hospital Español de México, Ejercito Nacional 613, C-302 colonia Granada, CP 11520, Mexico \\ ${ }^{2}$ Departamento de Postgrado, Escuela de Medicina Universidad La Salle México, Fuentes \#17, esquina Av. San Fernando, \\ colonia Tlalpan, CP 14000, Mexico \\ ${ }^{3}$ Unidad de Investigación en Epidemiología Clínica, UMAE Hospital de Pediatría CMN siglo XXI, Instituto Mexicano del Seguro Social, \\ Avenida Cuauhtemoc 330 colonia Doctores, CP 06720, Mexico
}

Correspondence should be addressed to Mario Enrique Rendón-Macías, mario.rendon@imss.gob.mx

Received 2 August 2010; Revised 23 September 2010; Accepted 13 October 2010

Academic Editor: Frans J. Walther

Copyright () 2010 José Iglesias-Leboreiro et al. This is an open access article distributed under the Creative Commons Attribution License, which permits unrestricted use, distribution, and reproduction in any medium, provided the original work is properly cited.

Objective. To analyze 25 years of mortality of extremely low-birth-weight (ELBW) neonates $(\leq 1000 \mathrm{~g})$ in a private hospital in Mexico City and to establish the current viability limit for ELBW neonates. Methods. We designed a prospective observational study of all ELBW neonates born between 1985 and 2009. Neonatal mortality, early neonatal mortality, and the 120-day mortality rate were analyzed in 5-year intervals by two categories of birth weight (501-750 g and 751-1000 g). Results. Among the 50,823 total births, 158 were ELBW $\left(3.1\right.$ per $\left.10^{3}\right)$. Neonatal mortality (death $\leq 28$ days) decreased for the $501-750$ g neonates from $88.9 \%$ ( $1985-$ $1989)$ to $55.6 \%(2005-1999)(P=.008)$ and for $751-1000$ g neonates also decreased from $50 \%$ to $5.3 \%(P=.002)$. The 120 -day mortality for neonates over $500 \mathrm{~g}$ diminished: $501-750 \mathrm{~g}$ neonates, $88.9 \%$ to $61.1 \%(P=.02)$ and for $751-1000 \mathrm{~g}$ neonates, $62.5 \%$ to $15.8 \%(P=.002)$. The highest viability limit was established in neonates who weighed $\geq 650 \mathrm{~g}$ and were $\geq 26$ weeks in gestational age. Conclusions. The survival of ELBW neonates has improved in Mexico particularly in private hospitals, and it was more evident over the years 2004-2009. These data suggest that it is possible to increase the ELBW neonates survive in developing counties.

\section{Introduction}

Advances in prenatal care and the availability of specialized centers have resulted in higher survival rates and a reduction in medium- and long-term complications for extremely lowbirth-weight (ELBW) neonates $[1,2]$. Favorable changes have been observed since the beginning of the 21st century due to the incorporation of prenatal strategies such as the use of prenatal corticoids, exogenous surfactants, different types of ventilation, better control of nosocomial infections, and early enteral feeding strategies [3]. In 2005, Itabashi et al. [1] reported an $87 \%$ 28-day survival of ELBW neonates and an $83 \%$ rate of discharge from the Neonatal Intensive Care Unit (NICU).

Regardless of these achievements, the increase in survival of ELBW neonates may be attributed to the presence of medical center facilities with neonatal care. In a recent Japanese study, the authors reported a 4.9-fold increased risk of death for a neonate born and treated in a medical facility outside of Tokyo, especially in centers that delivered 10 or less neonates per year [1]. The Neonatal Research Network (NICHD) suggested that the 120-day survival ranged from $38 \%$ to $76 \%$ for neonates who weighed $501-750 \mathrm{~g}$ and ranged from $74 \%$ to $94 \%$ for those who weighed $750-1000 \mathrm{~g}$ [4].

The most influential factors for survival may be the equipment in the NICUs and the skills of the personnel who handle the newborns $[5,6]$.

Few studies have reported on the survival of ELBW neonates in developing countries. In India, 501-750 g neonates have a $23 \%$ NICU survival and 751-1000 g neonates have a $61 \%$ survival [7]; in Thailand, 501-750 g 
neonates have a 20\% 28 days survival, and 751-1000g neonates have a $62 \% 28$ days survival. Interestingly, in both countries, the mortality rate for neonates weighing less than $500 \mathrm{~g}$ was $100 \%$ [8].

In 2000, Latin American countries saw neonatal mortality (<28 days) for 500-999g neonates decrease from $95 \%$ to $68 \%$ [9]. The $<28$ days survival for $500-750 \mathrm{~g}$ neonates improved from $19.1 \%$ to $21.8 \%$, and more importantly, the survival for $751-1000 \mathrm{~g}$ neonates improved from $73.4 \%$ to $75 \%[10,11]$. Interestingly, the survival differed by the type of facility; as Matijasevich et al. [12] described, the survival for $500-999 \mathrm{~g}$ neonates was $16.7 \%$ in public facilities and $53.2 \%$ in private facilities.

Mexico has few specialized centers for the care of ELBW neonates. Most of them are Social Security centers, which are either partially or completely funded by the government. Neonatal survival has been reported in only one of those centers: in 1999-2001, the <28 survival rate was $52.6 \%$ for ELBW neonates, including those weighing less than $500 \mathrm{~g}$; in 2003 the survival rate was $46 \%$ for the $600-1000 \mathrm{~g}$ neonates [10]. Also, this information is limited in time and of poor quality, and information from private hospitals is lacking.

The quality of health care varied for neonates in private medical centers in Mexico. Hospital Español de México is a tertiary care private facility with gynecology/obstetrics and perinatology services as well as specialized clinics for high-risk pregnancies, infertility, and assisted reproductive technology. The center also has a state-of-the-art NICU. This hospital receives the financial support of the Sociedad de Beneficencia Española (Spanish Beneficence Society). In addition, it is a teaching hospital that trains nursing personnel and medical residents in pediatrics, neonatology, and other specialties. The main objective of this study was to determine the mortality rate trends in 5-year periods from 1985 to 2009 for ELBW neonates at this NICU. In addition, to provide better information for parents and to perform objective evaluations to assist physicians in the decisionmaking process, we determined the viability limits in this facility.

\section{Methods}

The study population comprised all neonates with a birth weight of $1000 \mathrm{~g}$ or less, regardless of the gestational age, born alive between January 1st, 1985, and December 31st, 2009, in the Hospital Español de México. At this institution, all newborns who fit the criteria were admitted to the NICU. Currently, the hospital's Ethics Committee supports neonatal resuscitation for all newborns with signs of life at birth.

Once the neonates were stabilized, they were weighed using the same electronic scale (Tanita). The research team registered all events and comorbidities for the neonates during their stay at the hospital prior to discharge or death. This information was collected on a standardized form and then saved to a previously designed and codified electronic database. The stored data was periodically tested for reliability. The project was approved by the Hospital Research Committee.

\section{Definitions}

The mortality rate was calculated using the number of deaths that occurred among ELBW neonates during the first 28 days of life while at the hospital among the total number of ELBW newborns at the hospital. ELBW was defined as a birth weight 1,000 gram (g) or less. Neonatal early mortality rate was the ratio of the number of deaths during the first seven days of life to the total number of ELBW neonates. The 120-day mortality was calculated during the followup outside the hospital. All babies were reexamined monthly or revised during posterior hospitalization. Deaths were registered when parents notified to the research team or by telephone interview when someone missed a consultation, or when the baby died in hospital after a readmission.

Gestational age at birth was obtained from the mother's last menstrual period (LMP) or by ultrasound.

\section{Statistical Analysis}

The mortality rates were analyzed for each 5-year period, and trends were assessed. The patients were categorized into three strata: less than $500 \mathrm{~g}, 501-750 \mathrm{~g}$, and 751-1000 g. Mortality rates were calculated as percentages.

To compare the rates among the 5-year periods, Chisquare tests linear-by-linear association were performed. The characteristics of the groups were compared using Pearson's Chi-square test. Box and Whisker plots were made for each 5-year period to compare the length of hospital stay among died, survival, or transferred patients. The nonparametric Kruskal-Wallis test was used to compare the length of hospitalization between the neonates who died and those who survived. A $P$-value $<.05$ was considered statistically significant. All analyses were performed with SPSS 13 (Chicago, Ill).

To determine the variability limit in our hospital, we considered the combination of gestational age and the birth weight for which the 28-day survival after birth reached 50\% or more of the neonates with these conditions.

\section{Results}

During the study period, 50,823 infants were born, and among them 158 were ELBW neonates, reflecting a prevalence of 3.1 per $10^{3}$ live newborns at the hospital (95\% confidence interval $[95 \% \mathrm{CI}]: 2.6$ to 3.6 per $\left.10^{3}\right)$. The prevalence was significantly higher $(P<.001)$ during the most recent 5-year period; the rates varied from 3.3 per $10^{3}$ (95\% CI: 2.2 to 4.3 per $10^{3}$ ) in $1985-1989$ to 1.9 per 103 (95\% CI: 1.07 to 2.7 per $10^{3}$ ) in $1990-1994,1.8$ per $10^{3}$ (95\% CI: 0.8 to 2.7 per $\left.10^{3}\right)$ in $1995-1999,2.5$ per $10^{3}$ (95\% CI: 1.3 to 3.7 per $\left.10^{3}\right)$ in 2000-2004, and 6.0 per $10^{3}$ (95\% CI: 4.1 to 7.9 per $\left.10^{3}\right)$ in 2005-2009.

Across the five-year periods, there were no differences in the newborns characteristics such as sex, type of pregnancy (single, twins, or multiple), or gestational age (Table 1). 
TABLE 1: Characteristics of ELBW neonates across 5-year periods.

\begin{tabular}{|c|c|c|c|c|c|c|c|}
\hline & & $\begin{array}{c}1985-1989 \\
n=43\end{array}$ & $\begin{array}{c}1990-1994 \\
n=22\end{array}$ & $\begin{array}{c}1995-1999 \\
n=16\end{array}$ & $\begin{array}{c}2000-2004 \\
n=20\end{array}$ & $\begin{array}{c}2005-2009 \\
n=57\end{array}$ & $P$-Value \\
\hline \multicolumn{8}{|l|}{ Sex } \\
\hline & Male & $23(53.5 \%)$ & $10(45.5 \%)$ & $8(50 \%)$ & $9(45 \%)$ & $25(43.8 \%)$ & .90 \\
\hline & Female & $20(46.5 \%)$ & $12(54.5 \%)$ & $8(50 \%)$ & $11(55 \%)$ & $32(56.2 \%)$ & \\
\hline \multicolumn{8}{|c|}{ Gestation } \\
\hline & Single & $21(48.8 \%)$ & $14(63.6 \%)$ & $10(62.5 \%)$ & $14(70 \%)$ & $34(59.6 \%)$ & .09 \\
\hline & Twin & $22(51.2 \%)$ & $5(22.7 \%)$ & $5(31.3 \%)$ & $6(30 \%)$ & $21(36.8 \%)$ & \\
\hline & Multiple & 0 & $3(13.6 \%)$ & $1(6.3 \%)$ & 0 & $2(3.6 \%)$ & \\
\hline \multicolumn{8}{|c|}{ Weeks of gestational age } \\
\hline 21 & & 1 & 0 & 0 & 1 & 2 & .17 \\
\hline 22 & & 1 & 1 & 0 & 0 & 1 & \\
\hline 23 & & 4 & 1 & 2 & 2 & 3 & \\
\hline \multirow[t]{2}{*}{24} & & 2 & 3 & 0 & 3 & 4 & \\
\hline & $21-24$ & $8(18.6 \%)$ & $5(22.7 \%)$ & $2(12.5 \%)$ & $6(30 \%)$ & $10(17.5 \%)$ & \\
\hline 25 & & 5 & 3 & 2 & 1 & 7 & \\
\hline 26 & & 7 & 2 & 2 & 0 & 4 & \\
\hline 27 & & 6 & 1 & 0 & 3 & 5 & \\
\hline 28 & & 4 & 2 & 3 & 2 & 7 & \\
\hline 29 & & 10 & 2 & 1 & 4 & 5 & \\
\hline \multirow[t]{2}{*}{30} & & 4 & 3 & 5 & 4 & 9 & \\
\hline & $25-30$ & $34(79.1 \%)$ & $13(59.1 \%)$ & $13(81.3 \%)$ & $14(70 \%)$ & $37(64.9 \%)$ & \\
\hline 31 & & 0 & 1 & 0 & 0 & 2 & \\
\hline 32 & & 1 & 1 & 0 & 0 & 3 & \\
\hline \multirow[t]{2}{*}{34} & & 0 & 1 & 0 & 0 & 4 & \\
\hline & $31-34$ & $1(2.3 \%)$ & $13(13.6 \%)$ & $0(0 \%)$ & $0(0 \%)$ & $9(15.7 \%)$ & \\
\hline 35 & & 0 & 1 & 0 & 0 & 1 & \\
\hline \multirow[t]{2}{*}{37} & & 0 & 0 & 1 & 0 & 0 & \\
\hline & $36-37$ & $(0 \%)$ & $1(4.5 \%)$ & $1(6.3 \%)$ & $0(0 \%)$ & $1(2.5 \%)$ & \\
\hline \multicolumn{8}{|c|}{ Transfers } \\
\hline & $<8$ days & $3(6.9 \%)$ & 0 & 0 & $2(10 \%)$ & $1(2.5 \%)$ & .28 \\
\hline & $\geq 8$ days & 0 & 0 & 0 & 0 & $1(2.5 \%)$ & \\
\hline
\end{tabular}

${ }^{*}$ Chi-Square Pearson test

\section{Mortality Rate}

Table 2 presents the early-neonatal, neonatal, and 120day mortality rates by 5 -year periods. The rates decreased across the periods, and this trend was statistically significant. The most notable decrease was the $38.3 \%$ reduction (from $62.8 \%$ to $24.5 \%$ ) in the early-neonatal mortality rate; meanwhile, the neonatal and 120-day mortalities were reduced by approximately 34\% between the first and last periods.

This decrease in mortality was also observed among the different birth weight groups. None of the neonates weighing less than $500 \mathrm{~g}$ survived more than two days, representing $5 \%$ of the study population prior to 2005 . In the last period, the 120 days survival of two neonates in that birth weight category was achieved. Mortality for the 501-750 g neonates decreased by 50\% for early mortality and by $30 \%$ for the neonatal and 120-day mortality. The early mortality rate in the 751-1000 g neonates was reduced by $40 \%$; the neonatal and 120-day mortalities decreased by $45 \%$ and $37 \%$, respectively. Mortality differed among the 5 -year periods $(\mathrm{X} 2=17.18 ; 4 \mathrm{gl}, P=.002)$. In the first two periods (1985-1989 and 1990-1994), mortality was over $80 \%$ in the early neonatal period (Table 2). Mortality was not statistically different between the 1995-1999 and 2005-2009 periods; mortality was predominantly higher in the early-neonate group ( $\leq 8$ days) (U Mann Whitney, $P=.58)$ although the last period had the lowest mortality rate (Table 2). Mortality in 2000-2004 was again associated with early-neonate group in eight patients: one was less than $500 \mathrm{~g}$, five were in the 501-750 g range, and two were in the 751-1000 g range. In 2005-2009, among the 19 deceased patients, nine were early neonatal (56.2\%), three were neonatal $(18.7 \%)$, and four were postneonatal (25\%). 
TABLE 2: Early-neonatal, neonatal, and 120-day mortality in ELBW neonates by 5-year periods: 1985-2008.

\begin{tabular}{|c|c|c|c|c|c|c|}
\hline Birth weight & $\begin{array}{c}1985-1989 \\
n=43 \# \\
\text { dead } / \# \\
\text { total }(\%)\end{array}$ & $\begin{array}{c}1990-1994 \\
n=22 \# \\
\text { dead/\# } \\
\text { total }(\%)\end{array}$ & $\begin{array}{c}1995-1999 \\
n=16 \# \\
\text { dead/\# } \\
\text { total }(\%)\end{array}$ & $\begin{array}{c}2000-2004 \\
n=20 \# \\
\text { dead/\# } \\
\text { total }(\%)\end{array}$ & $\begin{array}{c}2005-2009 \\
n=57 \# \\
\text { dead/\# } \\
\text { total }(\%)\end{array}$ & $P$-value \\
\hline \multicolumn{7}{|c|}{ Early-neonatal mortality ( $\leq 8$ days) } \\
\hline $751-1000 \mathrm{~g}$ & $\begin{array}{c}11 / 23^{\S} \\
(47.0 \%)\end{array}$ & $\begin{array}{c}6 / 14 \\
(42.9 \%)\end{array}$ & $\begin{array}{c}2 / 13 \\
(15.4 \%)\end{array}$ & $\begin{array}{c}2 / 7^{\S} \\
(28.5 \%)\end{array}$ & $\begin{array}{c}2 / 28 \\
(7.1 \%)\end{array}$ & .0008 \\
\hline $500-750 \mathrm{~g}$ & $\begin{array}{c}15 / 18 \\
(83.3 \%)\end{array}$ & $\begin{array}{c}7 / 8 \\
(87.5 \%)\end{array}$ & $\begin{array}{c}2 / 3 \\
(66.7 \%)\end{array}$ & $\begin{array}{c}5 / 10^{\S} \\
(50.0 \%)\end{array}$ & $\begin{array}{c}9 / 23^{\S} \\
(39.1 \%)\end{array}$ & .0004 \\
\hline$<500 \mathrm{~g}$ & $\begin{array}{c}1 / 1 \\
(100 \%)\end{array}$ & - & - & $\begin{array}{c}1 / 1 \\
(100 \%)\end{array}$ & $\begin{array}{c}3 / 5 \\
(60.0 \%)\end{array}$ & - \\
\hline Total & $27(62.8 \%)$ & $13(59.1 \%)$ & $4(25 \%)$ & $7(35 \%)$ & $14(24.5 \%)$ & $<.0001$ \\
\hline \multicolumn{7}{|c|}{ Neonatal mortality ( $\leq 28$ days $)$} \\
\hline $751-1000 \mathrm{~g}$ & $\begin{array}{c}12 / 23^{\S} \\
(52.1 \%)\end{array}$ & $\begin{array}{c}7 / 14 \\
(50.0 \%)\end{array}$ & $\begin{array}{c}5 / 13 \\
(38.5 \%)\end{array}$ & $\begin{array}{c}3 / 7 \S \\
(42.8 \%)\end{array}$ & $\begin{array}{c}3 / 28 \\
(10.7 \%)\end{array}$ & .001 \\
\hline $500-750 \mathrm{~g}$ & $\begin{array}{c}16 / 18 \\
(88.9 \%)\end{array}$ & $\begin{array}{c}7 / 8 \\
(87.5 \%)\end{array}$ & $\begin{array}{c}3 / 3 \\
(100 \%)\end{array}$ & $\begin{array}{c}6 / 10^{\S} \\
(60.0 \%)\end{array}$ & $\begin{array}{c}13 / 23^{\S} \\
(56.5 \%)\end{array}$ & .005 \\
\hline$<500 \mathrm{~g}$ & $\begin{array}{c}1 / 1 \\
(100 \%)\end{array}$ & - & - & $\begin{array}{c}1 / 1 \\
(100 \%)\end{array}$ & $\begin{array}{c}3 / 5 \\
(60.0 \%)\end{array}$ & - \\
\hline Total & $29(67.4 \%)$ & $14(63.6 \%)$ & $8(50 \%)$ & $9(45 \%)$ & $19(33.3 \%)$ & .0003 \\
\hline \multicolumn{7}{|c|}{ 120-day mortality } \\
\hline $751-1000 \mathrm{~g}$ & $\begin{array}{c}15 / 23^{\S} \\
(65.2 \%)\end{array}$ & $\begin{array}{c}8 / 14 \\
(57.1 \%)\end{array}$ & $\begin{array}{c}6 / 13 \\
(46.2 \%)\end{array}$ & $\begin{array}{c}3 / 7^{\S} \\
(42.8 \%)\end{array}$ & $\begin{array}{c}4 / 27^{\S} \\
(14.3 \%)\end{array}$ & .0002 \\
\hline $500-750 \mathrm{~g}$ & $\begin{array}{c}16 / 18 \\
(88.9 \%)\end{array}$ & $\begin{array}{c}7 / 8 \\
(87.5 \%)\end{array}$ & $\begin{array}{c}3 / 3 \\
(100 \%)\end{array}$ & $\begin{array}{c}6 / 10^{\S} \\
(60.0 \%)\end{array}$ & $\begin{array}{c}14 / 23^{\S} \\
(60.8 \%)\end{array}$ & .01 \\
\hline$<500 \mathrm{~g}$ & $\begin{array}{c}1 / 1 \\
(100 \%)\end{array}$ & - & - & $\begin{array}{c}1 / 1 \\
(100 \%)\end{array}$ & $\begin{array}{c}4 / 5 \\
(80.0 \%)\end{array}$ & - \\
\hline Total & $32(74.4 \%)$ & $15(68.2 \%)$ & $9(56.3 \%)$ & $9(45 \%)$ & $22(38 \%)$ & $<.0001$ \\
\hline
\end{tabular}

${ }^{*}$ Chi-square linear-by-linear association tests. ${ }^{\S}$ Includes transferred patients.

\section{Hospital Stay}

Figure 1 shows that there were few changes in the length of hospital stay during the analyzed periods. For surviving patients, the mean length of stay in the hospital varied from 50 to 90 days. There were no statistically significant differences among the 5 -year periods (Kruskal-Wallis test, X2 $=1.17 ; 4 \mathrm{gl}, P=.88)$.

\section{Transfers}

Only six patients were transferred to other centers for neonatal care; there were no statistically significant differences regarding the length of hospital stay (Kruskal-Wallis, X2 = $5.45 ; 2 \mathrm{gl}, P=.17)$.

\section{Viability Limits}

Figure 2 presents the correlations between weight and gestational age of the neonates; these correlations are stratified by survival and by 5 -year periods. Lines represent the survival limits, and it was observed that for the 1985-1989 period, the mortality was higher than $90 \%$ in neonates weighing less than $780 \mathrm{~g}$ who were born prior to week 28 of gestation. The limit of survival has been shortened through the different periods, especially after 2000. Currently, the viability limits may be established for neonates weighing less than $650 \mathrm{~g}$ that were born prior to week 25 of gestation.

\section{Discussion}

To our knowledge, this is the first study that reports the mortality rates in ELBW neonates in a private hospital in Mexico. As mentioned above, the survival of these children is mainly attributed to the available resources, the expertise of the personnel, and the number of ELBW neonates cared for by the facility $[1,13,14]$. Our data describe the progressive achievements in our institution during the last few years and indicate the future needs and requirements to achieve better outcomes. Currently, we consider the survival of the babies born at our institution is similar to that reported in developed countries $[2,4,13,15,16]$ (Table 3 ).

Worldwide, ELBW survival may be evaluated with regard to birth weight or gestational age, [2] due to their impact on survival. However, birth weight, rather than gestational age has been recommended as the preferable predictor of survival because the gestational age of preterm infants is difficult to calculate. Therefore, as previous studies have suggested $[2,13]$, we designed our study to assess survival based mainly on the birth weight of infants. 
TABLE 3: Preterm mortality rates in different countries.

\begin{tabular}{|c|c|c|c|c|c|c|}
\hline \multirow{2}{*}{ Country } & \multirow{2}{*}{$n$} & \multirow{2}{*}{ Mortality rates* } & \multirow{2}{*}{ Year(s) } & \multicolumn{3}{|c|}{ Mortality rate stratified by birth weight (in grams) } \\
\hline & & & & $<500$ & $501-750$ & $751-1000$ \\
\hline \multirow{2}{*}{$\operatorname{Japan}^{1}$} & \multirow{2}{*}{3065} & Neonatal & 2005 & $47.5 \%$ & $16.1 \%$ & $6.5 \%$ \\
\hline & & NICU & 2005 & $57.5 \%$ & $21.6 \%$ & $8 \%$ \\
\hline \multirow{2}{*}{ United Kingdom and USA ${ }^{2}$} & \multirow{2}{*}{4172} & DR & $1996-2000$ & $52 \%$ & - & - \\
\hline & & NICU & & $62 \%$ & - & - \\
\hline \multirow[t]{2}{*}{ Israel $^{5}<751 \mathrm{~g}$} & \multirow[t]{2}{*}{97} & $\begin{array}{l}\text { NICU hospital } \\
\text { inborn }\end{array}$ & 2003-2006 & \multicolumn{2}{|c|}{$44 \%$} & - \\
\hline & & $\begin{array}{l}\text { NICU hospital } \\
\text { outborn }\end{array}$ & & \multicolumn{2}{|c|}{$36 \%$} & - \\
\hline $\mathrm{USA}^{4}$ & 8312 & 120 days & 1997-2002 & - & $45 \%$ & $12 \%$ \\
\hline \multirow{3}{*}{ Mexico (Private hospital) } & \multirow{3}{*}{40} & Early neonatal & 2005-2009 & $60 \%$ & $39.1 \%$ & $7.1 \%$ \\
\hline & & Neonatal & & $60 \%$ & $56.5 \%$ & $10.7 \%$ \\
\hline & & 120-day & & $80 \%$ & $60.8 \%$ & $14.3 \%$ \\
\hline Germany $^{15}<1000 \mathrm{~g}$ & 8677 & NICU & $2000-2005$ & & $15 \%$ & \\
\hline \multirow{2}{*}{ Finland ${ }^{13}$} & \multirow{2}{*}{$\begin{array}{l}529 \\
511\end{array}$} & Neonatal & $1996-1997$ & $89 \%$ & $55 \%$ & $23 \%$ \\
\hline & & & 1999-2000 & $75 \%$ & $45 \%$ & $16 \%$ \\
\hline \multirow{2}{*}{ Spain $^{16}$} & \multirow{2}{*}{28} & Early neonatal & $2000-2003$ & - & $11.1 \%$ & $15.7 \%$ \\
\hline & & Neonatal & & - & $33.3 \%$ & $21 \%$ \\
\hline Turkey $^{17}$ & 135 & NICU & 1997-2000 & - & $91.7 \%$ & $21.1 \%$ \\
\hline Uruguay $^{11}$ & 130 & NICU & 2001-2004 & $100 \%$ & $80.9 \%$ & $25 \%$ \\
\hline Mexico (Public System) ${ }^{10}$ & 250 & Early neonatal & 1999-2001 & $81.8 \%$ & $78.2 \%$ & $26.6 \%$ \\
\hline Norway ${ }^{18}$ & 638 & NICU & 1999-2000 & $90 \%$ & $58 \%$ & $28 \%$ \\
\hline India ${ }^{7}$ & 137 & NICU & 1994-2000 & $100 \%$ & $77 \%$ & $39 \%$ \\
\hline Thailand $^{8}$ & 22 & Neonatal & 2003-2006 & - & $80 \%$ & $48 \%$ \\
\hline
\end{tabular}

*Early neonatal ( $\leq 8$ days), neonatal ( $\leq 28$ days) NICU (Neonatal Intensive Care Unit), DR (Delivery Room), 120-day (survival of $\leq 120$ days). Inborn: newborn born in their hospital, outborn: newborn born in other hospital.

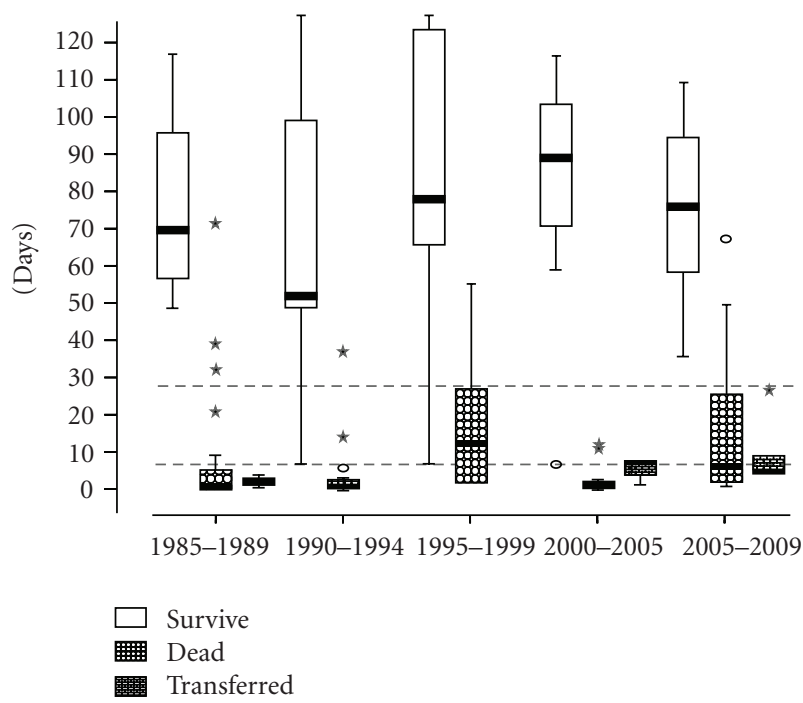

Figure 1: Length of hospital stay in the NICU by ELBW infants according to survival or death by 5 -year periods.

Similar to other reported rates worldwide, our hospital has seen an increase in ELBW and/or extremely premature neonates. Global reports suggest that prevalence of ELBW neonates increased from 0.3 to $2 \%$ of all newborn infants [4].
The increase in ELBW newborns has been evident since the 1980s and 1990s, with an estimated annual increase of $20 \%$. At our institution, we have also seen a significant increase in ELBW neonates through the years, from (in the 1980s) 3.3 per $10^{3}$ live births to 6.0 per $10^{3}$ live births (in the last four years). This $45 \%$ increase is much higher than that published in studies from the US and Europe $[4,15,16]$ and could be a consequence of several factors particular to our facilities which include the resuscitation of every newborn with or without signs of life, independently of the gestational age or birth weight. This practice has varied since 1985; in the mid-1990s, neonatal resuscitation programs were implemented.

Another considerable factor is that our institution is a referral center for high-risk pregnancies, specializing in assisted pregnancies, under a joint agreement between the obstetrical and neonatology services. So, it is very important for us to ensure that every conception achieved has the opportunity to live, no matter the weight or gestational age. Lastly, the increase in the incidence of ELBW newborns may be partly related to the prevalence of multiple pregnancies, mainly as a consequence of assisted reproduction programs within the hospital.

Our data suggest a statistically significant clinical decrease in the ELBW infant mortality rate during the studied period, especially during the last 5-year period. Some of 


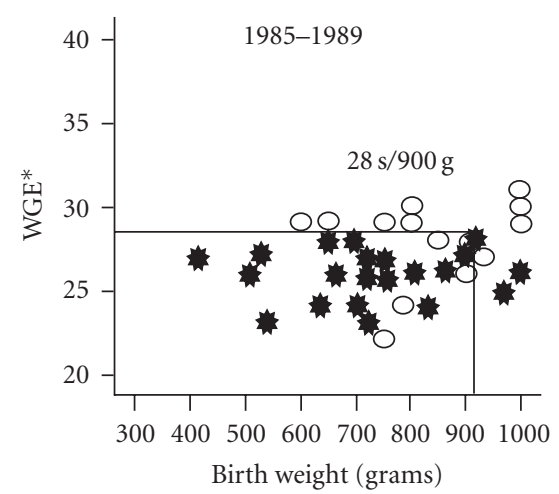

(a)

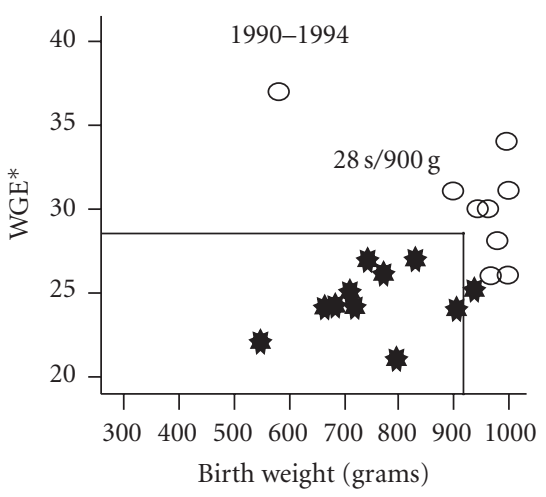

(b)

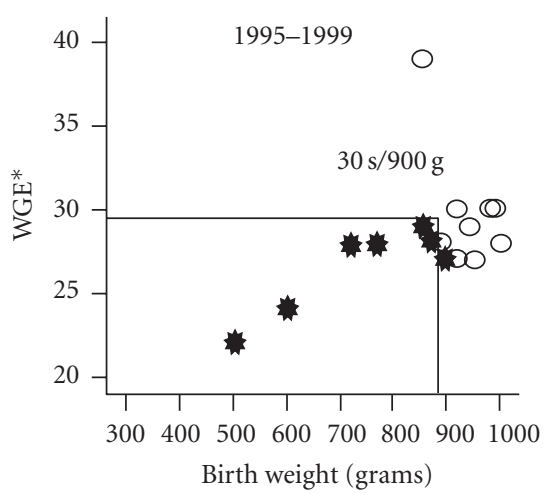

(c)

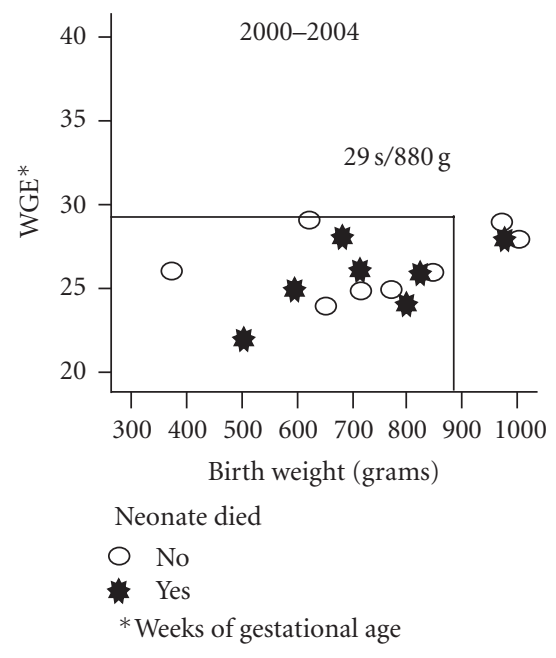

(d)

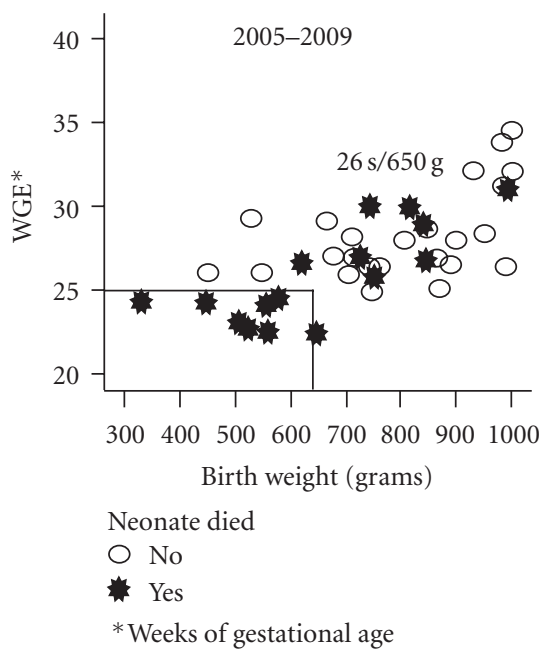

(e)

FIgURE 2: Viability margins by 5 -year periods in relation to birth weight and gestational age.

the major factors that may have contributed to this decrease were: the implementation of a training program for doctors and residents to learn how to resuscitate neonates, the use of exogenous surfactant and prenatal steroids, new modalities in assisted ventilation, the incorporation of nitric oxygen, the implementation of plans for early enteral nutrition, and the incorporation of breastfeeding. These strategies have proven to be effective in other countries where mortality has decreased and where the quality of life of surviving infants has improved $[1,4]$.

As reported for other countries, we observed a higher neonatal mortality in the early stage of newborn life, particularly within the first 24 hours $[1,2,11,13,17]$. The stability of neonates that weigh less than $750 \mathrm{~g}$ is critical, and instability may cause approximately $80 \%$ of the deaths. Whether to resuscitate these neonates has been a controversial issue because of high hospital costs in addition to a high risk for later complications [4].

Currently, we are working to decrease these risks and to improve the quality of life as well as to evaluate late morbidity. With regard to the need for additional improvements, Figure 2 shows that the length of stay in the hospital ranged from 80 to 110 days for most of the neonates, with a minimal reduction during the study. The main goal, as documented in other studies, is to release the neonate in the best condition to his/her home to reduce the risk of rehospitalization $[4,17,18]$.

In this study, an important objective (with medical and legal implications) was to determine the possible viability limits of ELBW neonates in hospitals that usually work with medical insurance services. We showed that the viability margins or limits considered during situations in which the survival was higher than $50 \%$ were reduced in the most recently studied 5-year period. Although the viability limit from this study does not present any legal implications at the present time, the limit (gestational age $\geq 25$ weeks and birth weight $\geq 650 \mathrm{~g}$ ) could be a clinical indicator to confer with the parents on making medical decisions. Since 2000, in our NICU, all newborns have a standardized neonatal intensive care protocol, regardless of their birth weight or gestational age; so, we think the mortality rate has not been influenced by discontinuation of intensive care because of poor prognosis.

The strengths of this study included its review of a 25year span of time, using an acceptable sample, and having more than $95 \%$ of the data available to study ELBW neonates. Of course, this study may not be representative of all private 
TABLE 4: Morbidity in 35 infants with birth weight < 1000 grams: 2005-2009.

\begin{tabular}{llc}
\hline Diagnosis & $n$ & $(\%)$ \\
\hline Bronchopulmonary dysplasia & 7 & $(20 \%)$ \\
Intracranial hemorrhage (III-IV) & 7 & $(20 \%)$ \\
Retinopathy (III-IV) & 3 & $(8.5 \%)$ \\
Hydrocephaly & 2 & $(5.7 \%)$ \\
Short bowel syndrome & 1 & $(2.8 \%)$ \\
\hline
\end{tabular}

hospitals in Mexico, and there may have been selection bias because this hospital was chosen by mothers with better health and higher socioeconomic status; also, when consider weight groups, they were small. However, we have provided additional information to help the Beneficencia Española face the challenge of maintaining a first-level center for these patients; therefore, it is necessary to communicate the current implications of caring for ELBW neonates. Future work will need to address the survival conditions in the medium and long terms because mortality is not the only quality indicator of improvement at NICU's; for instance, in 35 patients followed up in the period 2000-2009, the main chronic conditions were bronchopulmonary dysplasia and intracranial hemorrhage (Table 4).

\section{Conclusions}

Early- and medium-term mortality in neonates has significantly decreased in our hospital since 1995, particularly in the last 5-year period without a modification in the length of hospital stay. The viability limits have been reduced, and there is a high probability of survival for $650 \mathrm{~g}$ neonates or those equal or greater to 26 weeks of gestation.

\section{Acknowledgments}

J. Iglesias-Leboreiro, R. H. José, and R.-M. M. Enrigueparticipated in the development of the protocol, execution, analyses, and the writing of the paper. I. Bernardez-Zapata contributed development of the protocol and to the writing of the paper. G.-M. Rocco contributed in the execution of the study and final data analysis.

\section{References}

[1] K. Itabashi, T. Horiuchi, S. Kusuda et al., "Mortality rates for extremely low birth weight infants born in Japan in 2005," Pediatrics, vol. 123, no. 2, pp. 445-450, 2009.

[2] M. Hack, D. Wilson-Costello, H. Friedman, G. H. Taylor, M. Schluchter, and A. A. Fanaroff, "Neurodevelopment and predictors of outcomes of children with birth weights of less than 1000 g 1992-1995," Archives of Pediatrics and Adolescent Medicine, vol. 154, no. 7, pp. 725-731, 2000.

[3] M. C. Walsh, B. H. Morris, L. A. Wrage et al., "Extremely low birthweight neonates with protracted ventilation: mortality and 18-month neurodevelopmental outcomes," Journal of Pediatrics, vol. 146, no. 6, pp. 798-804, 2005.
[4] A. A. Fanaroff, B. J. Stoll, L. L. Wright et al., "Trends in neonatal morbidity and mortality for very low birthweight infants," American Journal of Obstetrics and Gynecology, vol. 196, no. 2, pp. 147.e1-147.e8, 2007.

[5] I. Arad, R. Braunstein, and B. Bar-Oz, "Neonatal outcome of inborn and outborn extremely low birth weight infants: relevance of perinatal factors," Israel Medical Association Journal, vol. 10, no. 6, pp. 457-461, 2008.

[6] L. W. Doyle, E. Bowman, C. Callanan et al., "Changing availability of neonatal intensive care for extremely low birthweight infants in Victoria over two decades," Medical Journal of Australia, vol. 181, no. 3, pp. 136-139, 2004.

[7] S. Narayan, R. Aggarwal, A. Upadhyay, A. K. Deorari, M. Singh, and V. K. Paul, "Survival and morbidity in extremely low birth weight (ELBW) infants," Indian Pediatrics, vol. 40, no. 2, pp. 130-135, 2003.

[8] S. Sritipsukho, T. Suarod, and P. Sritipsukho, "Survival and outcome of very low birth weight infants born in a university hospital with level II NICU," Journal of the Medical Association of Thailand, vol. 90, no. 7, pp. 1323-1329, 2007.

[9] P. Sarasqueta, "Mortalidad infantil por malformaciones congénitas y prematurez en la Argentina: análisis de los criterios de reducibilidad," Archivos Argentinos de Pediatría, vol. 104, pp. 153-158, 2006.

[10] M. A. Rivera-Rueda, G. Hernandez-Trejo, I. Llano-Rivas et al., "Análisis de la mortalidad neonatal precoz en el Instituto Nacional de Perinatología (1999-2001)," Perinatología y Reproducción Humana, vol. 19, pp. 13-21, 2005.

[11] M. Costas, S. Dominguez, G. Gimbruno, and M. Martell, "Morbi-mortalidad y crecimiento de los niños con muy bajo peso al nacer hospitalizados," Archivos de Pediatría del Uruguay, vol. 76, pp. 289-304, 2005.

[12] A. Matijasevich, F. C. Barros, and J. K. Díaz-Rossello, "Atención de la salud en niños de muy bajo peso al nacer en Montevideo, Uruguay: comparación entre los sectores públicos y privados," Pediatria (São Paulo), vol. 77, pp. 313320, 2001.

[13] V. Tommiska, K. Heinonen, L. Lehtonen et al., "No improvement in outcome of national wide extremely low birth weight infant populations between 1996-1997 and 19992000," Pediatrics, vol. 119, pp. 29-36, 2007.

[14] B. R. Vohr, L. L. Wright, A. M. Dusick et al., "Center differences and outcomes of extremely low birth weight infants," Pediatrics, vol. 113, no. 4, pp. 781-789, 2004.

[15] C. Geffers, S. Baerwolff, F. Schwab, and P. Gastmeier, "Incidence of healthcare-associated infections in high-risk neonates: results from the German surveillance system for very-low-birthweight infants," Journal of Hospital Infection, vol. 68, no. 3, pp. 214-221, 2008.

[16] V. Díaz, J. Berzosa, and E. Alonso, "Mortalidad, morbilidad inmediata y factores de riesgo en recién nacidos con extremado bajo peso al nacimiento," Progresos de Obstetricia y Ginecología, vol. 48, pp. 165-171, 2005.

[17] W. Meadow, G. Lee, K. Lin, and J. Lantos, "Changes in Mortality for Extremely Low Birth Weight Infants in the 1990s: implications for Treatment Decisions and Resource Use," Pediatrics, vol. 113, no. 5, pp. 1223-1229, 2004.

[18] J. F. Lucey, C. A. Rowan, P. Shiono et al., "Fetal infants: the fate of 4172 infants with birth weights of 401 to 500 gramsthe Vermont Oxford Network experience (1996-2000)," Pediatrics, vol. 113, no. 6, pp. 1559-1566, 2004. 
[19] B. Atasay, A. Günlemez, S. Ünal, and S. Arsan, "Outcomes of very low birth weight infants in a newborn tertiary center in Turkey, 1997-2000," Turkish Journal of Pediatrics, vol. 45, no. 4, pp. 283-289, 2003.

[20] T. Markestad, P. I. Kaaresen, A. Rønnestad et al., "Early death, morbidity, and need of treatment among extremely premature infants," Pediatrics, vol. 115, no. 5, pp. 1289-1298, 2005.

[21] S. Anthony, L. D. Ouden, R. Brand, P. Verloove-Vanhorick, and J. B. Gravenhorst, "Changes in perinatal care and survival in very preterm and extremely preterm infants in the Netherlands between 1983 and 1995," European Journal of Obstetrics Gynecology and Reproductive Biology, vol. 112, no. 2, pp. 170-177, 2004. 


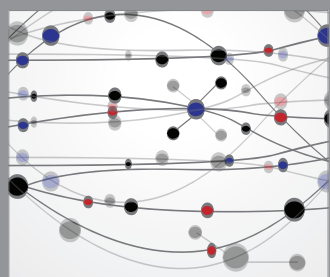

The Scientific World Journal
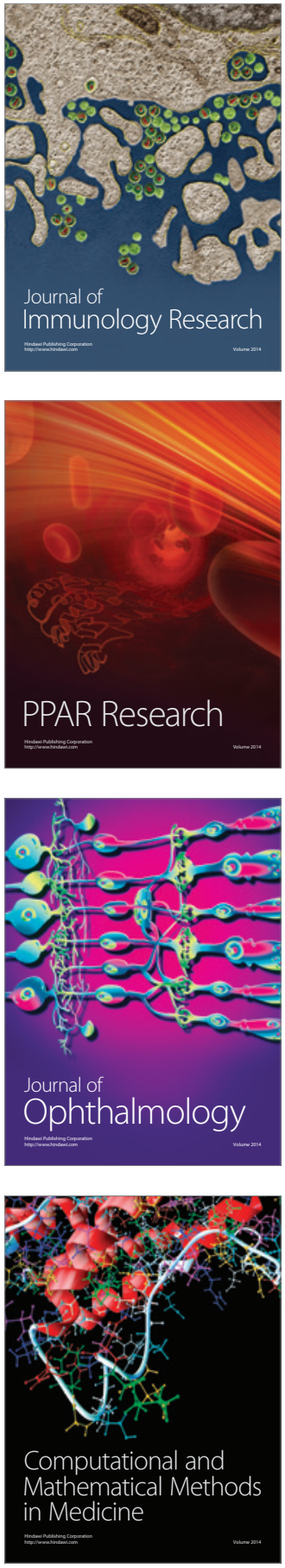

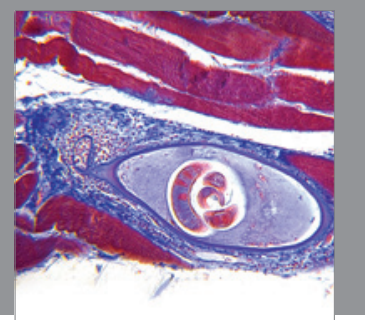

Gastroenterology

Research and Practice
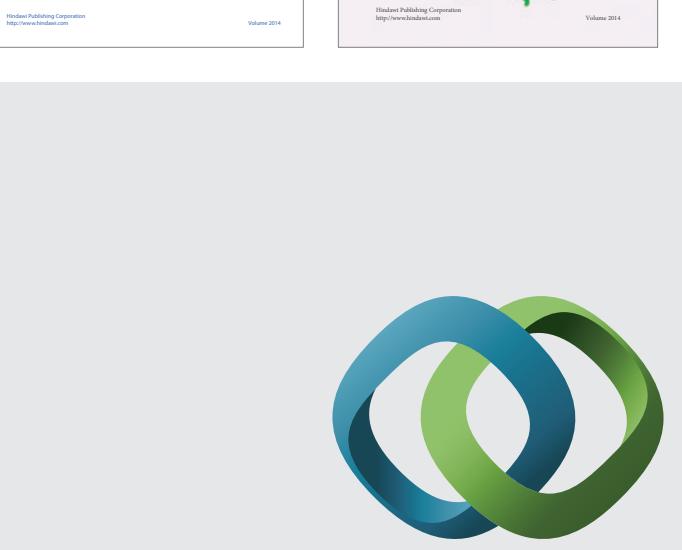

\section{Hindawi}

Submit your manuscripts at

http://www.hindawi.com
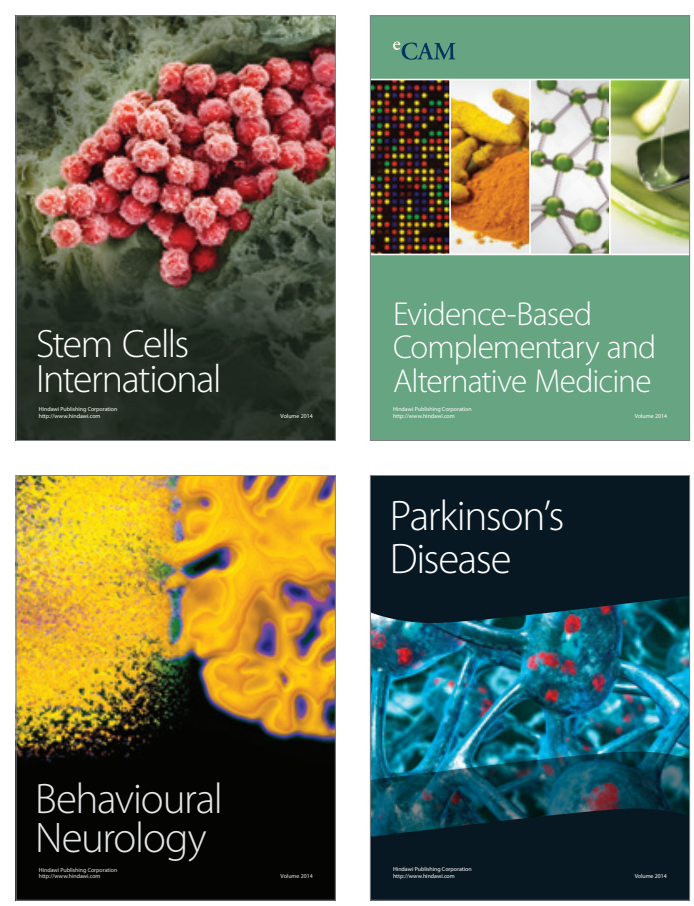

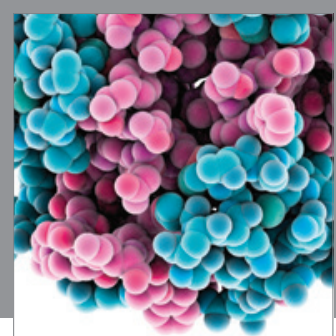

Journal of
Diabetes Research

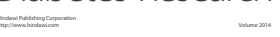

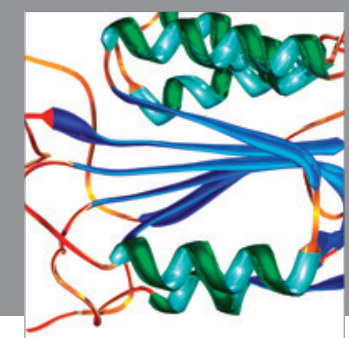

Disease Markers
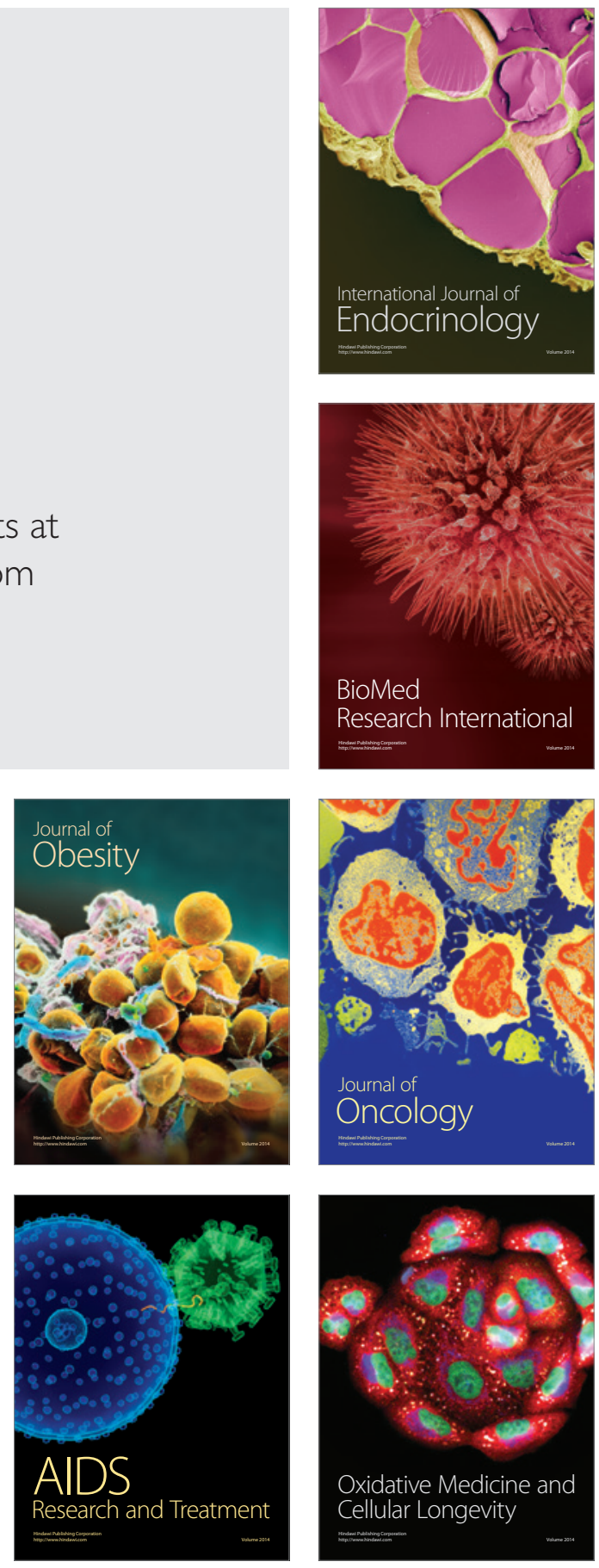